\title{
Evaluation of ecological and economic efficiency of environmental management in construction
}

\author{
Vadim Bespalov ${ }^{1}$, Tatyana Kushnarenko ${ }^{1}$, and Oksana Paramonova ${ }^{1 *}$ \\ ${ }^{1}$ Don State Technical University, 344022, 1 Gagarina sq., Rostov-on-Don, Russia
}

\begin{abstract}
In the way of thinking of a modern man we are seeing a paradigm shift, namely, there is a gradual shift in priorities: ecological ones become primary, and economic ones - secondary. Progressive mankind more often pays attention to the preservation of natural resources, to environment purity, thereby trying to find the optimal ratio in solving environmental and economic issues. Analyzing the modern development of the sectors of the world national economy, we observe the prolonged dominance of economic priorities over environmental ones, which, in turn, cannot but negatively affect the state of the flora and fauna of our planet. These circumstances create, strange as it may seem, positive conditions for accelerating the creation of economic mechanisms for environmental protection aimed at reducing the anthropogenic impact of various factors on the environment. The economic efficiency of this activity is expressed through the prevented damage from environmental pollution. Construction is a branch of national economy which is always associated with interference in the environment; therefore, assessing the environmental and economic effectiveness of environmental protection activities, observing environmental protection measures is very important for this industry and society as a whole.
\end{abstract}

\section{Introduction}

Currently, both theoretical and practical issues of environmental and economic efficiency of environmental activities remain highly relevant [1-6]. We are observing in the construction industry the positive impact of economic criteria of environmental activities effectiveness on the formulation of environmental and economic research, on development of a modern methodological apparatus. Assessing the environmental and economic effectiveness of environmental measures is a task of increased scientific and practical complexity, the solution of which is directly related to the general theory of determining the effectiveness of investment projects. For these purposes methodological recommendations were developed and approved for assessing the effectiveness of investment projects, in accordance with which indicators of economic efficiency of investment projects and

\footnotetext{
*Corresponding author: paramonova_oh@mail.ru
} 
environmental measures were determined. An environmental and economic justification is mandatory on the territory of the Russian Federation when developing justifications for investments in the construction of various objects of urban infrastructure (residential and public buildings, industrial enterprises, structures for various purposes), one of the main stages of which is to carry out environmental impact assessment for the project (EIA).

\section{Theory or experimental methods}

The main direction of increasing the efficiency of urban development activities [1-5,7-8] and resources, both material and financial, aimed at developing this type of activity, is the selection of environmental protection measures, which is a cost-effective set of environmental safety provision. To implement such a set of measures, as a rule, significant volumes of capital investments and operating costs are required $[4,7,8]$. The main criteria include environmental and economic efficiency parameters characterizing the effectiveness of eliminating (weakening) the negative impact of construction activities on the environment[6-8]. Environmental and economic studies are conducted, usually with limited financial, physical and other resources in order to, firstly, identify the major ways to achieve the quality of environment at the least costs and, secondly, to determine priority and, respectively, the sequence of these events.

The obtained result (effect) from the relation of the effective action to the expended efforts characterizes the concept of "efficiency". The environmental, social and economic effectiveness of various environmental protection measures is the effectiveness of environmental protection activities. As a result of optimization of production activities of enterprises favourable conditions are formed to provide for safe environmental situation and prevention of economic damage from anthropogenic environmental impact, as well as for additional revenue of the enterprise - and this manifests economic impact of environmental activities. Ecological efficiency of environmental activities should be assessed by capital and operating costs for the activities, by indices characterizing degrees of emissions treatment, discharge of pollutants into the atmosphere, residual level of environmental pollution and other ecological and economic indicators $[4,6,8]$.

Unlike the operation of the object of urban infrastructure and its effect on the environment, the process of construction itself takes a relatively short time, so the definition of the object economy is an important and necessary stage in the process of implementation of which it should be evaluated, how the appearance and operation of the facility will affect the environment. During periods of construction and operation of urban infrastructure a considerable damage is inflicted to the population and environment of human life, flora and fauna, natural landscape, cultural and historical heritage. For this purpose, it is necessary to calculate the compensation for the damage caused. The resulting environmental, economic and social results will be a measure of the effectiveness of environmental measures. Achieved environmental result will manifest in improving the environment: reduction of such indicators as concentration of polluting substances, radiation, noise levels, as well as reduction of negative environmental impact of various other adverse events.

Rational use of natural resources, labor and materials for the purpose of loss reduction and/or prevention of their total or partial destruction in the production and nonproduction spheres as well as in the sphere of personal consumption is achieved through the manifestations of economic results[4-8]. In case we observe an increase in the physical standard characterizing the population; disease reduction; improvement of working and resting conditions; increasing the life expectancy of people and the period of active activity 
of the working population; preservation of natural monuments, history and culture; etc., then, accordingly, we see a positive manifestation of social results. Ecological and economic effect as a result of construction comes after a period of from three to five years, the multiplicative manifestation of which we can observe in the existing system of urban landscape beautification, in assessment of the environmental situation around us, in the assessment of the available results of the environmental measures.

In the construction industry we observe how assessment of environmental and economic efficiency of environmental activities synergies different types of economic evaluations, thus involving in the process assessment of indicators of production and business activity such as: current and capital expenditures; the amount of damage detected (current, potentially possible); produced commodities (works and services) in accrual terms; the amount of secondary material resources transferred for disposal; tax payments, fines and compensation for environmental pollution; transaction costs; value of costs related with purification of secondary waste and their use $[1,5,8]$.

Nature protection activities and assessment of their environmental and economic efficiency is associated with various economic indicators which at the same time are the main criteria of the evaluation, such as cost-benefit ratio; internal rate of return and net present value. It should be noted that prior to submission of documentation designed to support production and business activities for the state ecological expertise at all stages of its preparation performance of assessment is necessary. In the course of environmental and economic research, the main task is to take into account the implementation of environmental measures, which, in turn, rarely bring quick environmental results, in a certain sequence, and also, to achieve the desired environmental quality, the concretization of methods and ways, the use of which will allow planned activities with the greatest economic benefit. Based on this understanding, we see that in the case of determining the economic efficiency of environmental costs in order to compare the planned benefits and actual costs, it is advisable to use the discount coefficient. In this case, the discount coefficient is identified with the bank (loan) interest rate, thereby creating the conditions for bringing the actual costs and planned results to a progressive cost. Based on the experience used by international organizations and almost all European banks, discount rates usually range from 8 to 12 percent. As a comparative cost-effectiveness of environmental costs or method of determining actual costs, we recommend using a method based on a "costeffectiveness", the distinctive feature of which is considered to be the development of an optimum way, the use of which will allow to a maximum degree minimize the costs associated with the achievement of the intended goal, pushing into the background the determination of positive effect (benefit) from the implementation of the measure in order to compare the received result with the costs incurred. The use of the discount coefficient, in our opinion, is optimal in the matter of choosing a method that allows to bring the value of the total current costs and capital investments to relatively not only the same indicators, but to reasonably moderate. This approach is most interesting in the case when it is necessary and quite difficult to determine the synergistic effect as the economic benefit from the implementation of the environmental project.

Performing calculations of the assessment of the economic efficiency of investment projects countries with developed market relations use a number of indicators, including:

1. indicators of net present benefit/fair value - NPB (net present benefit);

2. investment profitability index - BCR (benefit-cost ratio);

3. indicators of the internal rate of return/rate of return - IRR (internet rate of return).

Determining the effectiveness of environmental protection measures is another important task that is directly related to assessing the environmental and economic effectiveness of environmental protection in construction. Comparing the process of determining possible economic damage to the environment and the population of 
construction activities with the process of determining other economic indicators of production, we see that the first process is the most labor-intensive and complex. In case of similar projects, when substantiating investments, the costs associated with the prevention of negative consequences and the implementation of mandatory environmental protection measures are determined $[1,2,4,5,8]$.

In economic theory, in determining the overall (absolute) economic efficiency of environmental protection measures and its improvement, indicators are usually used that characterize the full economic effect, the sum of indicators that caused this effect - that is capital investment and operating costs. The ratio of the total economic effect to the sum of capital investments and operating costs determines the indicator of absolute economic efficiency.

\section{Results and Discussion section}

Full economic effect is determined [2,3] by determining the value of prevented environmental damage, which is defined as difference between evaluations of economic damage caused by environmental pollution before and after the environmental events, efficiency of which is calculated by the formula (1):

$$
\text { Eeem }=\sum \Delta \mathrm{R} / \mathrm{AE}
$$

where Eeem is the effectiveness of environmental measures; $\Sigma \Delta \mathrm{R}$ is the amount of damage reduction; $\mathrm{AE}$ is annual expenses for environmental protection measures.

The value of the net economic effect is a necessary indicator of the effectiveness of various measures aimed at environmental protection, which is equal to the remainder of the full economic benefit less actual expenses, related to the implementation of environmental protection measures. By comparing the actual costs with the economic result achieved due to the work performed, the economic effect of environmental measures is calculated. The obtained result is reflected in indices characterized by liquidated and/or prevented economic damage from the breach or loss of resources, and depends on the amount of actual costs aimed at these activities. If the economic result exceeds the actual costs associated with its achievement, we can conclude about the economic efficiency of environmental protection measures. The economic effect is characterized by the difference between the result obtained and the actual costs. Formula (1) reveals the economic content of the justification of the problem of environmental protection measures. In the event that there will be savings from reducing the damage associated with environmental impact, and its amount will be not less (or better more) the amount of additional costs aimed at preventing negative consequences from such a negative impact, then only in this case a compromise optimum will be achieved. The calculation methodology will have an individual component nature for each natural object: soil, water, air [1-3].

In the course of construction activities all environmental activities should be economically feasible and ensure, firstly, the intended use of the actual costs to implement various environmental protection measures; secondly, when assessing the costs and results of environmental protection measures take into consideration time factor; and thirdly, when economically substantiating environmental measures, an inter-sectoral approach should be followed when justifying them and taking into account the savings in actual costs aimed at improving the environment.

If the profit and the volume of production are reduced by the amount of the established damage associated with the environmental impact, then the cost rate will increase, which will entail, accordingly, a proportional decrease in indicators of profitability, labor productivity and capital productivity. If the basic volume of production is maintained and the costs caused by the change or increase in production assets increase due to 
environmental protection funds, then it can be assumed that it is possible to prevent and/or significantly reduce the amount of damage to the environment. The evidence of compliance with the high profitability of environmental protection funds is the significant superiority of the volume of investments associated with the use of modern technologies and/or treatment devices over the volume of investments to achieve environmental protection effects and reduce environmental damage. In the event that environmental costs are absorbed from the total costs, for example, the costs of treatment facilities, various criteria and methods for assessing the effectiveness of environmental protection measures can be applied, which will allow to determine, firstly, the phased implementation and, secondly, relative values, the use of which will help to identify production processes which are insufficient or unacceptable from environmental point of view and economically disadvantageous for achievement of final economic objectives [1-5,8].

In accordance with Article 36 of the Federal Law "On Environmental Protection" “... when designing buildings, structures and other facilities, the standards of permissible anthropogenic environmental load must be taken into account, measures to prevent and eliminate environmental pollution, as well as ways of disposing of production and consumption wastes, resource-saving, low-waste, waste-free and other best existing technologies shall be applied that contribute to environmental protection, restoration of environment, rational use and reproduction of natural resources ..." [1] . The law establishes the level of permissible standards of negative impact on the environment, compliance with which ensures public environmental safety, as well as the rational use and reproduction of natural resources in the context of sustainable development of construction activity. The selected stages of the development of project documentation in each case affect the environmental justification of construction activities. The Environmental Doctrine of the Russian Federation notes that “... sustainable development, high quality of life and health of the population can be achieved only if natural systems are maintained and the environmental quality is maintained. One of the priority directions for ensuring sustainable nature management in this document is the maintenance of environmentally balanced economic activity, the conservation and restoration of biological diversity and landscapes in economically developed and urbanized territories" [2].

Environmental justification includes a number of documents: an application of intent; justification of investment in construction; construction project; construction organization project (COP); documents for obtaining a license for certain types of activities. The objects of environmental justification include: design solutions related to the choice of technology, production capacity, the range of products (services), etc.; substantiation of ecological safety (possible environmental risk), planned activities, including assessment of the impact of the object on the environment during normal operation and when accidents occur; the choice of location (site) of the facility; methods and volumes of natural resources withdrawal; application for a license; level of environmental hazard of products and waste generated; planned environmental measures; ways of organizing construction works. Goal of development of environmental justification is to prevent and/or reduce environmentally harmful environmental impact. This goal is unified "... during various events: reconstruction, expansion, technical re-equipment of enterprises; conservation and liquidation of facilities; during (capital and non-capital) construction; installation of non-stationary objects " [1-3,8].

When substantiating ecological safety and technological solutions and choice of a place (or variants of places) for placement of a construction project, taking into account various environmental factors benchmark estimate of the facility's impact on the environment (both quantitative and qualitative) acts as a platform, which justifies the need for carrying out the phase of "Project of planned economic and other activity impact assessment on the 
environment" [1-3, 8]. This stage allows, first of all, to determine the various consequences (economic, environmental, social) of the implementation of the investment construction project, in addition, to assess the level of investment costs aimed at ensuring environmental safety in the zone of influence of the facility. For the purpose of concretizing these goals, within the framework of this project the sections "Environmental Protection and Sanitary and Hygienic Requirements" and "Technological Regulations for the Process of Construction and Demolition Waste Management" are being developed, the content of which includes " environmental justification of technological, environmental protection, construction, architectural and planning other design solutions based on a detailed assessment (quantitative and qualitative) of the environmental impact of the facility. Ensuring the prevention of environmental degradation, reducing the potential impacts of the planned economic activity to the level regulated by the relevant norms, rules, standards, and in their absence, restrictions on the use of natural resources, with the highest rates of investment efficiency in the project " $[1-3,8]$ form goals of the stage.

\section{Conclusions}

An integral part of the effectiveness of the entire economy is the effectiveness of environmental activities of society. Not always the interests of society can coincide with the interests of production regarding economic benefits. Wasteful use of natural resources, pollution of the environment contradicts the interests of society, thereby causing a stir within the population, but high production cost-effectiveness can be achieved. When analyzing the environmental activities of various organizations and enterprises, one cannot but note the fact that their interest in this type of activity is at a fairly low level, and the state has not fully developed a mechanism that promotes motivation for this interest. In addition, it should be noted that the amount of investment in environmental protection measures is inferior, and sometimes even significantly, to the amount of costs aimed at compensating the environmental damage. This applies to economically compensated damages. But sometimes the result of irrational nature management can be irreparable damage. Unfortunately, such a "skillful" use of nature and its resources is characteristic not only for our country, at present it is a problem for all progressive mankind. The development and use of modern technologies, providing, first of all, the use of resourcesaving low-waste and non-waste technologies, should be the basis for solving the problems that have arisen, thereby inspiring hope for the prevention of an environmental global catastrophe.

The development and implementation of advanced technologies is currently favored by economically developed countries, involving both science and the results of advanced national and international experience in these processes, thereby ensuring a constant increase in investment. Another important point contributing to the development of investment activity is a quick return on investment from one to five years, which confirms the economic benefits and social justification. Unfortunately, considering the activities of domestic organizations and enterprises, often we can but see the opposite picture. Currently, the financing system and the level of legal liability do not fully contribute to the fact that organizations and enterprises take care of preventing environmental damage and the environment and implement a set of environmental protection measures.

\section{References}

1. O. D. Elvan, Envir. Sci. Pol., 84, 1-6 (2018) doi.org/10.1016/j.envsci.2018.02.008 
2. M. Zeleňáková, L. Zvijáková, Envir. Imp. Asse. Rev., 62, 76-89 (2017) doi.org/10.1016/j.eiar.2016.10.003

3. N. Wang, M. Ma, G. Wu, Y. Liu, X. Chen, J. Cle. Prod., 225, 664-674, (2019) doi.org/10.1016/j.jclepro.2019.03.315

4. G.Feng, C.Tian, S.Li, F.Xu, Proc. Eng., 205, 702-708 (2017) doi.org/10.1016/j.proeng.2017.09.888

5. P. Shaikh, S. Muhammad, H. Shaikh, M. Kumar, F. Shaikh, I. Bhatti, Environmental Assessment of Green Buildings, Reference Module in Materials Science and Materials Engineering, (2019)

6. Po-H. Chen, Ch. Ong, Sh. Hsu, J. Cle. Pro. 39, 750-760 (2016) doi.org/10.1016/j.jclepro.2016.08.109

7. V. I. Bespalov, O. S. Gurova, N. S. Samarskaya, E. P. Lysova, Biosciences, Biotechnology Research Asia, 11, 1615-1620 (2014) doi.10.13005/bbra/1560

8. V. I. Bespalov, A. V. Konovalov, A. N. Kabarukhina, Scientific Proceedings of ISPC "Fundamental and Applied Questions of Science and Education", 7-8 (2016) 